\title{
Tort Law Culture in the United Kingdom: Image and Reality in Personal Injury Compensation
}

\author{
Richard Lewis and Annette Morris*
}

\begin{abstract}
This article highlights two contrasting sets of images of tort that are dominant in UK culture. The first set reflects various aspects of the traditional portrayal of justice, which depicts tort as an independent 'natural' system of rules of universal application forming the foundation of a just society. The second group of images is more recent and relates to the perceived development of a damaging compensation culture. Focusing on personal injury litigation, we show, in different ways and to different degrees, how these portrayals differ from the reality of tort in practice. In explaining how tort actually operates we reveal significant features of the culture of tort. In practice it is heavily influenced by institutional arrangements: the importance of both welfare provision and liability insurance is highlighted, and the effects of a 'no-win no-fee' claims market are examined. The article reveals that the operation of tort is very much affected by commercial interests and the economic demands of the institutions which surround it. Overall we conclude that the cultural images of tort examined fail to reflect how the system of compensation for personal injury actually operates in practice.
\end{abstract}

Although culture is very difficult to define, ${ }^{1}$ we can say that tort rules, procedures and institutions both reflect and help determine the broad culture of the society of which they are a part. Concepts such as wrongdoing, causation, compensation and justice depend upon a cluster of popular beliefs and attitudes which are in turn

\footnotetext{
* Cardiff Law School, Cardiff University, Museum Avenue, Cardiff CF10 3AX, Wales, UK

${ }^{1} R$ Cotterrell, Law, Culture and Society (2006) 83.
} 
moulded by the legal system. ${ }^{2}$ To help with problems of definition, Nelken suggests: 'Legal culture, in its most general sense, is one way of describing relatively stable patterns of legally oriented social behaviour and attitudes. ${ }^{3}$ One aim of this article is to illustrate how the tort system reflects particular social institutions and practices. But a more important theme is in conflict with this aim: we point to a dissonance between social attitudes and the reality of the tort system in practice. That is, we examine perceptions of tort derived from commonly held views about how the system of justice ought to operate and we contrast how tort, in practice, often does not correspond to these views.

This article is written in two parts. In the first part we consider images of tort deriving from traditional portrayals of justice. We set out seven commonly held views about the operation of the personal injury litigation system and then we contrast what actually happens in practice. We note the rhetoric and the social attitudes derived from long-held cultural views of how the legal system is supposed to operate and we then compare the reality. We start by reflecting upon the scope of tort principles. Next we consider who brings and defends personal injury cases and what role is played by courts and judges in their resolution. We then consider how the key principle of fault is interpreted in practice and how the operation of insurance affects traditional perceptions of how justice is delivered. Finally, we look at the reasons why damages are awarded and what amounts are paid. Overall, we set out the seven commonly held views of tort and then, by examining the actual practice of personal injury, we undermine them.

In the second part of this article we look at another set of images which contrast with those set out in the first part. These images portray the tort system in a very critical way, depicting it as a burden that undermines rather than underpins society. It is widely perceived that tort has encouraged a damaging compensation culture. Our propensity to claim is said to have increased to such an extent that we can no longer

2 DM Engel/JS Engel, Tort, Custom and Karma (2010) 11.

3 D Nelken, Law, Liability and Culture, in: DM Engel/M McCann (eds), Fault Lines: Tort Law as Cultural Practice (2009) 22. 
accept personal responsibility for our misfortunes. The system is thought to be awash with unmeritorious claims which have been prompted by an ambulance-chasing entourage offering to work on a 'no-win no-fee' basis. Exaggeration and fraud are to the fore and non-existent or unmeritorious injuries are compensated. As in the first part of the article, although with less force, we then show how these images have become distorted from reality. In particular, the majority of injured people still do not go on to claim compensation despite being encouraged to do so through widespread 'no-win no-fee' advertising. The exception arises in the context of road traffic accidents, where there is a strong culture of claiming. The significant increase in the number of personal injury claims over the last forty years is largely attributable to an increase of such claims. Whilst the extent of spurious and fraudulent claiming has generally been exaggerated, again, in the context of road traffic accidents complaints have more foundation. We examine why such a strong culture of claiming has developed in the context of road traffic accidents as compared with other types of claim. In conclusion, having shown how traditional and modern portrayals of tort differ from the reality, we show how tort in practice is heavily influenced by institutional arrangements.

The scope of this article is limited in so far as it examines only the role of tort in providing compensation for personal injury. Of course we are aware of the much wider scope that exists for tort claims. But if we were also to consider, for example, culture in relation to defamation and freedom of speech, or in relation to nuisance and the environment, we could not have constructed the present coherent framework for analysis. We are content with our present, more limited focus of study: after all personal injury litigation is by far the most significant area of tort for the everyday work of the legal profession in the UK and many other countries.

\section{Tort and the traditional portrayal of justice}

\section{A. Tort law is universal and applies to all accidents and injuries}

A powerful image of the traditional portrayal of justice is that of the universal application of the law to all citizens. All are equally subject to the law and all can equally benefit or be penalised by it. To law students this is reinforced early in their study of tort by the analysis given of the negligence formula. They are told that one of 
the reasons for the success of that cause of action is that it can potentially apply to all sorts of accidents and injuries. In addition, the formula itself is a relatively simple one: instructions to juries based upon finding liability using the 'reasonable man' formula were easy to give and understand no matter how complex the situation. Similarly, the 'neighbour' test used by judges to determine whether a duty of care was owed has a superficial simplicity and appears capable of being used in very diverse circumstances.

In reality the actual scope of actions in tort for personal injury is severely limited. Only certain types of injury are likely to attract compensation. This is because the claims brought are much affected by the incidence of compulsory insurance so that the accidents that are compensated closely match the areas where liability insurance is to be found. Road and work accidents predominate because those are the two major areas where tort insurance is compulsory. ${ }^{4}$ In 2011 - 2012 they constituted $88 \%$ of all the claims that were brought for personal injury, with motor accidents comprising $80 \%{ }^{5}$ of the total and employers' liability $8 \% .^{6}$ They dominate the practice of tort even though they constitute, at best, only about a half of all accidents, ${ }^{7}$ and some

${ }^{4}$ The lack of coherent policy behind compulsory insurance was traced in $R$ Lewis, The Duty to Insure (2004) 154 New Law Journal (NLJ) 1474. See also C Parsons, Employers Liability Insurance How Secure is the System? (1999) 28 Industrial Law Journal (ILJ) 109.

${ }^{5}$ Department for Work and Pensions, Compensation Recovery Unit - Performance Statistics $<$ http://www.dwp.gov.uk/other-specialists/compensation-recovery-unit/performance-andstatistics/performance-statistics $>$.

${ }^{6}$ Ibid. Thirty four years ago the Pearson Commission also recorded that road and employment claims comprised $88 \%$ of all claims. Report of the Royal Commission on Civil Liability and Compensation for Personal Injury (1978, cmnd 7054, chairman Lord Pearson - hereinafter: Pearson Commission) vol 2 table 11. Atiyah suspected that the relative proportion of claims had not changed twenty years later: PS Atiyah, The Damages Lottery (1997) 99. However, the relative importance of employment claims has now declined considerably. They comprise only $8 \%$ of all claims compared to $45 \%$ in 1978. By contrast road accidents have increased considerably, expanding from $45 \%$ to $80 \%$ of all claims.

7 Pearson Commission (fn 6) vol 2 table 57. 
surveys suggest that they are much less important than this. ${ }^{8}$ More common accidents are those in the home, or suffered in the course of leisure activities or in playing sport, and yet very few of these result in any damages award. ${ }^{9}$ It was estimated that there were 7.8 million accidents in the home in 1999 but in only $0.5 \%$ of these was there the potential for a successful tort claim. ${ }^{10}$ Therefore, although work and transport injuries dominate the tort system, they are not representative of accidents in general.

All this means that the place where you are injured is crucial. Accidents in areas not covered by liability insurance are extremely unlikely to be compensated. According to one study conducted over thirty years ago, whereas one in four road accident victims and one in ten work accident victims were compensated in tort, only one in 67 injured elsewhere did so. ${ }^{11}$ Overall, only one accident victim in 16 who was incapacitated for three days or more was compensated by the tort system. However, if we concern ourselves only with serious injuries, tort was much more important: where an accident caused incapacity for work for six months or more, almost a third of victims received tort damages. However, this increased significance of tort was then severely undermined: the importance of the tort system is reduced tenfold if account is taken of those suffering disablement not from accidents alone, but from all causes, including congenital illness and disease. ${ }^{12}$ For a variety of reasons this group is much less able to claim in tort than accident victims, ${ }^{13}$ and common law damages plays an even more limited role in their compensation.

${ }^{8}$ In Australia they are less than a fifth according to H Luntz/D Hambly, Torts: Cases and Commentary (5th edn 2002) 4.

9 D Harris et al, Compensation and Support for Illness and Injury (1984) table 2.1.

${ }^{10}$ Datamonitor, UK Personal Injury Litigation (2003) 79.

${ }^{11}$ Pearson Commission (fn 6) vol 1 table 5. Compare similarly the landmark RAND study by $D R$ Hensler et al, Compensation for Accidental Injuries in the United States (1991) 122.

${ }^{12}$ Atiyah (fn 6) 100.

${ }^{13}$ J Stapleton, Disease and the Compensation Debate (1986). 
The limited scope of tort compensation can be contrasted with the much wider ambit of the welfare state. Although only a small part of public expenditure upon welfare is paid to accident victims, ${ }^{14}$ the amount greatly exceeds the total damages paid by the tort system. In reality tort is very much the 'junior partner' of the social security system. ${ }^{15}$ The Pearson Commission in 1978 found that seven times as many accident victims received social security payments as opposed to tort damages for their injuries and that the total benefit obtained by them was double the sum of all damages awarded. ${ }^{16}$

These figures must not be taken to imply that the tort and social security systems are mutually exclusive; in fact they are closely linked. The person who succeeds in his damages claim is more likely to be in receipt of a wider range of welfare benefits than the more typical accident victim who is unable to claim in tort. ${ }^{17}$ The existence of the welfare state has provided injured people with the basic sustenance needed to undergo the sometimes lengthy process of pursuing a claim for damages at common law. If accident victims had not been able to obtain this immediate support from the benefit system it is unlikely that the action for common law damages - with all its delays, costs and complexity - would have survived long in the twentieth century. For that

${ }^{14}$ Pearson Commission (fn 6) vol $1 \S 87$ roughly estimated that in 1978 only about $6 \%$ of public expenditure upon welfare was directed towards accident victims. This represented about $2 \%$ of total public expenditure at that time (welfare provision then being a third of the total). The calculation took into account the cash benefits and costs of administration of the social security system and added to it the costs of hospital and medical services.

${ }^{15}$ Pearson Commission (fn 6) vol $1 \S 1732$.

${ }^{16}$ Pearson Commission (fn 6) vol 1 table 4 suggested that in 1977 there were about 215,000 recipients of damages totalling $£ 200$ million whereas the social security system paid out about $£ 420$ million to one and a half million people. By 1988 although more people were receiving tort damages, the relative importance of the schemes remained about the same. The Lord Chancellor's Department, Report of the Review Body on Civil Justice (1988, cm 394) § 391.

${ }^{17}$ In a survey nine out of ten recipients of damages of $£ 20,000$ or more also received, on average, three different social security benefits: Law Commission Personal Injury Compensation: How Much Is Enough? (Report No 225, 1994) table 901. 
reason the tort system can be seen as parasitic upon the welfare state. It is similarly dependent upon liability insurance. ${ }^{18}$ This is far from the image of tort as an independent 'natural' system of rules of universal application supposedly forming the foundation of a just society. Tort in practice is limited in its scope, partial in its application and very dependent upon existing systems of welfare and insurance administration.

\section{B. Tort claims for personal injury are often brought and defended by individuals}

This image seems largely self-evident. Corporations cannot suffer personal injury, only individuals can, and although many of them will seek to attribute responsibility to their employer or the state or other complex body, the majority will name another individual as liable for their injury. Tort case names are replete with the surnames of individuals; organisations appear much less frequently. This individualism is said to be one of the most distinctive features of tort. When combined with a subjective approach in the assessment of loss and claimant need, this individualism is said to make tort distinct from the provision for injury made by the welfare state. However, this image of tort again needs to be qualified considerably when viewed from the perspective of practice.

\section{Defendants}

Let us first consider those who are the real defendants in the great majority of cases: the insurers. They are the paymasters of the tort system and are responsible for $94 \%$ of tort compensation for personal injury. ${ }^{19}$ Although not named in the law reports and therefore rarely mentioned in tort textbooks, they are the 'elephant in the living

\footnotetext{
${ }^{18}$ J Steele, Risks and Legal Theory (2004) 36: 'Insurance "technology" underlies the whole practice of tort law.' Without insurance, it is probable that tort liability itself could not survive. See JG Fleming, The American Tort Process (1988) 21; R Lewis, How Important Are Insurers In Compensating Claims for Personal Injury In The UK? (2006) 31 The Geneva Papers on Risk and Insurance 323.

${ }^{19}$ Pearson Commission (fn 6) vol $2 \S 509$.
} 
room. ${ }^{20}$ That is, they are almost always present and dominate proceedings, and yet judges and jurists rarely discuss this fact. ${ }^{21}$ Although it is true that the majority of claims for injury are brought against defendants who are individual people, almost all of them are insured against their liability. Similarly, most employers, companies and organisations who are sued are also insured. The result is that in nine out of ten cases the real defendants are insurance companies, with the remainder comprising large self-insured organisations or public bodies, such as government departments and health authorities. It is extremely rare indeed for an uninsured individual to be the real defendant.

The important centres of personal injury practice are therefore insurers' buildings, rather than courts of law, or even lawyers' offices. In the last decade the number of such insurance centres has declined because of company mergers and greater specialisation. The work has been concentrated in particular localities. Consolidation in the general liability insurance market has resulted in it being dominated by only eight major companies, although there are more than fifty other smaller firms issuing policies. $^{22}$ More than half of the larger general insurers are foreign-owned. ${ }^{23}$ For motor insurance there were over 350 companies authorised to transact motor insurance but only 65 companies and 11 Lloyds syndicates actively did so. The ten largest motor insurers control three quarters of the market. ${ }^{24}$ Thus the more than a

${ }^{20} R$ Lewis, Insurers and Personal Injury Litigation: Acknowledging 'The Elephant in the Living Room’ [2005] Journal of Personal Injury Law (JPIL) 1.

${ }^{21} R$ Lewis, Insurance and the Tort System (2005) 25 Legal Studies (LS) 85.

${ }^{22}$ C Parsons, An Analysis of Current Problems in the UK Liability Insurance Market, Office of Fair Trading Report (OFT 659a, 2003) § 5.6.

${ }^{23}$ IMAS Corporate Finance (on behalf of TheCityUK and UK Trade \& Investment), UK Financial Services: Ownership, Value and M\&A Developments (2012).

${ }^{24}$ Ernst and Young, Bringing Profitability back from the Brink of Extinction: A Report on the UK Retail Insurance Market (Chartered Insurance Institute, 2011) 17. The Association of British Insurers found the percentage to be two thirds in its Response to the Greenaway Review of Compulsory Motor Insurance and Uninsured Driving (London: ABI, 2004) annex B. 
million people who suffered personal injury last year and brought tort claims came up against very few real defendants.

Policyholders in practice cede complete control over their case to their insurer and thereafter usually play little or no part in the litigation process. For example, Harry Street, the late Professor of Law at Manchester University and author of Street on Torts, revealed that he was once a defendant in a case but only discovered that it had been determined on appeal when he read about it in a newspaper. ${ }^{25} \mathrm{He}$ had played no part in the proceedings. Insurers in practice determine the litigation tactics that are used and how any defence is to be conducted. This means, for example, that they commonly make admissions without the consent of the insured, ${ }^{26}$ and they can settle cases in spite of objection from the policyholder. ${ }^{27}$ Further examples of the insurer's control over a personal injury case are given below.

\section{Claimants}

When we consider claimants, it cannot be contested that the individual named in the lawsuit is the person who has suffered injury. However, bringing a tort action is also very much influenced by the insurance background to the claim. Here we concentrate upon claimants' abilities to appoint their own legal representation in order to bring the claim. We know that most tort defendants are liability insurance policyholders and have no choice in the law firm appointed to defend them; if they wish to take advantage of the indemnity provided by the policy they must accept the representation provided. It might be thought that claimants, in contrast, have complete freedom to choose their own lawyer. However, this is far from the case.

${ }^{25}$ DW Elliott/H Street, Road Accidents (1968) 209.

${ }^{26}$ T Goriely/R Moorhead/P Abrams, More Civil Justice? The Impact of the Woolf Reforms on PreAction Behaviour (2002) 90.

${ }^{27}$ However, this very wide discretion given to insurers to conduct the litigation behind the insured's back is subject to some limit as recognised in Groom v Crocker [1939] 1 King's Bench (KB) 194. 
The reason for the limited choice lies in the rapid expansion in recent years of before-the-event (BTE) insurance. ${ }^{28}$ This is the claimant's own insurance against future legal costs that he took out before the accident which caused him injury. It is sometimes referred to as legal expenses insurance. Almost three in five adults now have some form of this insurance. ${ }^{29}$ Over 18 million drivers hold it as part of their motor insurance and 14 million householders as part of their buildings and contents insurance. In total these number about 22 million people. ${ }^{30}$ In addition, for example, about 7 million workers are entitled to BTE benefits resulting from their trade union membership, although this is a declining number. This wide penetration of the market has been achieved largely because BTE has been sold as an additional benefit to be included in existing motor liability or household insurance. In effect, there has been a great deal of inertia selling. Few people opt to take out stand-alone BTE policies, but they commonly accept legal expenses cover as part of a wider package.

BTE limits the freedom to choose one's own lawyer because claimants are directed by the insurer to use firms which are on the insurer's approved panel. ${ }^{31}$ In return for limiting their costs and ensuring that the cases are dealt with efficiently, panel firms are guaranteed a constant flow of work by the insurer. Firms also pay the insurer a referral fee for each case received. Significant sums are thus received by the insurer but the referral arrangement may not be of similar benefit to the claimant. The law firm may be located a considerable distance from the injured person's home and resort must be had to electronic and written communications. In practice, therefore, the firms are not only the choice of the insurer rather than the claimant but they also

${ }^{28}$ R Lewis, Litigation Costs and Before-The-Event Insurance: The Key to Access to Justice? (2011) 74 Modern Law Review (MLR) 272.

${ }^{29}$ FWD Group, The Market for 'BTE' Legal Expenses Insurance (2007) § 3.3.

${ }^{30}$ Mintel International Group, Legal Expenses Insurance (2008).

${ }^{31}$ H Blundell, Free to Choose? BTE Legal Expenses Insurance and Freedom of Choice [2004] JPIL 93. Freedom to choose is supported by Directive 87/344/EEC on the coordination of laws, regulations and administrative provisions relating to legal expenses insurance (OJ L 185, 4.7.1987, 77-80) and it is supported domestically by the Insurance Companies (Legal Expenses Insurance) Regulations 1990 SI No 1159 and the recent case of Brown-Quinn and another v Equity Syndicate Management Limited and Motorplus Limited [2011] England \& Wales High Court (EWHC) 2661. 
may not facilitate the personal assistance and contact that the claimant may need. In spite of this, injured people in practice are pressured into accepting a panel solicitor, ${ }^{32}$ and the claim is thus brought through an insurance sponsored lawyer. Overall, we can see that it is far from the case that claims in tort are either brought or defended by individuals as the traditional view implies.

\section{Tort claims are determined in court by judges aided by lawyers and juries}

An enduring image of tort law contained in popular views of justice is that of a bewigged judge, aided by similarly adorned barristers, carefully sifting the evidence to come to a just decision. The judge and barristers are invariably male with the latter distinguished by the finery of their robes. They sit in the formal surroundings of a courtroom, often wood-panelled, which affects in many ways the justice that is delivered. ${ }^{33}$ Behind the barristers sit a phalanx of sober suited solicitors. Some people may also conjure up a box of twelve people good and true to form a jury by which their peers are to be judged. The formality is at once respected and feared. Although helping to ensure impartial adjudication untainted by emotional response, the atmosphere is so alien to many claimants that they will do almost anything to avoid it. Fear of having to appear in court and face cross-examination is a major reason for claimants being too ready to accept the very first offer of settlement that is put to them. This also explains why some claims are not even pursued at all. However, it is a fear with little foundation because cases today are never decided by a judge and jury in court. The involvement of these symbols of justice is very limited when we consider how tort cases are actually determined.

We have already seen that the great majority of cases are really defended by insurance companies. The high cost of litigation, when combined with the small size of claims, ensures that it is simply not economic to utilise the legal profession and its accoutrements in the way that the popular imagination conceives. In practice, it is insurers who decide whether a case merits the very exceptional treatment of being taken to a court hearing. A key statistic of the tort system reveals how unusual it is for

\footnotetext{
${ }^{32}$ P Abram, In Sure Hands? (2002).

${ }^{33}$ L Mulcahy, Legal Architecture: Justice, Due Process and the Place of Law (2011).
} 
a court to become involved: $98 \%$ of cases are settled before they are even set down for trial, and, of the few that do receive a trial date, most are concluded before that formal hearing takes place. ${ }^{34}$ In one survey only 5 out of the 762 'ordinary' cases went to trial. ${ }^{35}$ In effect, insurers allow trial judges to determine only $1 \%$ of all the claims made. In these rare cases the judge receives no assistance from that other major symbol of popular justice: the jury. Although juries remain an important feature of personal injury litigation in the USA, they were abolished in the UK in all but very exceptional cases in 1934 having fallen into disuse many years before. A 'Runaway Jury' simply cannot happen in a personal injury case in the UK. ${ }^{36}$

If a case does reach court and is determined by a judge, the decision is unlikely to be challenged further. Few cases are appealed to a higher court. The result is that when the senior judiciary are called upon they are left to adjudicate upon a small fraction of what are, by then, very untypical cases indeed. Whether an appeal court is to be given an opportunity to examine a point of tort law may depend upon the insurer because, if it serves the insurer's purpose for doubt to remain, the claimant can be paid in full and threatened with a costs award if the action is continued. ${ }^{37}$ By their control of settlement tactics and which cases are taken to appeal, insurers have shaped

${ }^{34}$ Pearson Commission (fn 6) vol 2 table 12.

${ }^{35}$ P Pleasence, Personal Injury Litigation in Practice (1998) 12. Earlier, Harris et al (fn 9) had suggested that as many as $3 \%$ of cases might go to trial. However, even in cases involving very substantial awards of damages, where resort to formal proceedings is more likely, courts are unlikely to be involved. In a study of cases where $£ 150,000$ or more was paid by insurers in 1987 and 1988 only $10 \%$ of payments were the result of formal court orders. Even these orders mostly related to children or patients for whom court approval of their settlements is required by law so that they cannot be dealt with out of court. See P Cornes, Coping with Catastrophic Injury (1993) 20.

${ }^{36}$ J Grisham, The Runaway Jury (1996).

${ }^{37}$ As recognised in Davis v Johnson [1979] Appeal Cases (AC) 264, at 278. But see the failed attempt to prevent the House of Lords considering important causation issues in relation to asbestos liability in Fairchild v Glenhaven Funeral Services Ltd [2002] 1 AC 32 discussed by K Oliphant in: H Koziol/BC Steininger (eds), European Tort Law 2002 (2003) 142, no 13, and in (2002) 12 (3) Association of Personal Injury Lawyers Newsletter 19. 
tort principles and what happens in practice. This is far from the popular image of how tort law has been created and what effect it has.

If we turn our attention to cases that are settled out of court, as opposed to formally adjudicated, we find that it is still insurers that determine the extent that lawyers and formal procedures become involved. Increasingly they are seeking to settle cases at an early stage without resorting to the issue of court documents. In one survey of major insurers it was estimated that, because of earlier settlement, the number of cases disposed of only after the issue of formal proceedings had declined by a third. ${ }^{38}$ Of course it has always been the case that the great majority of claims are settled informally: over thirty years ago $86 \%$ of cases were being settled without formal proceedings in the form of a writ being issued. ${ }^{39}$ Now even more cases are being settled at an early stage.

Insurers are avoiding not only judges, courts, and court procedures but also lawyers. Defence lawyers are being bypassed and more work is being done in-house by insurers. In addition, in an effort to increase specialisation and cut costs, insurers have tried to ensure that fewer law firms act for them. For example, in 2004, AXA insurance company announced that it had reduced by half the number of law firms defending its cases. Similarly, over a period of four years, the Zurich insurance company decimated the number of firms representing its policyholders in catastrophic cases: only four firms now defend such cases for this large insurer. Much of the work being done in personal injury law firms is now being carried out by unqualified or partly qualified paralegal personnel. It is feared that, as a result of proposed reforms, non-lawyers at claims management firms could be left in charge of even complex personal injury claims. ${ }^{40}$ The image of tort law as being regularly administered by highly trained lawyers in a formal environment is thus very far from the reality.

\section{Tort liability is largely dependent upon proof of fault and findings of law}

\footnotetext{
${ }^{38}$ Goriely/Moorhead/Abrams (fn 26) 159.

${ }^{39}$ Pearson Commission (fn 6) vol 2 table 12.

${ }^{40}$ Anon.,Case Conundrum? (2011) 161 NLJ 1569.
} 
The extent that popular culture requires fault to be established in order for liability to be found is uncertain. It is clear that wrongdoing has been the fundamental force which has justified the continued expansion of the law of tort. However, the notion of responsibility goes far beyond that of fault and this is reflected in the strict liability regimes found in the law of tort. These areas of non-fault liability are usually limited in their practical effect but have widespread popular support especially in the area involving injuries at work. For example, it has been shown that people commonly think that employers should pay for injuries caused to their workforce even in the absence of any fault on their part. ${ }^{41}$ However, overall the fault principle plays a major role in determining the popular response as to whether compensation should be paid. In the absence of fault, for example, property owners are rarely found liable. The fault principle has a great effect upon students of the law of tort because of the disproportionate emphasis it receives in tort textbooks. Common law negligence is the core element of tort teaching; strict liability, especially if deriving from statute, is a neglected area of study. As a result, the standard response to the inquiry is compensation payable?' very often is 'it depends whether fault can be proven.'

However, the hold that fault maintains over the popular and student response towards compensation in tort is not reflected in the actual practice of law. Via liability insurance, tort in practice provides a structure for processing mass payments of small amounts of compensation. In processing these routine claims insurers decide which elements of damage they will accept or contest. The key fact here is that it is unusual for them to contest liability; one study revealed that insurers' files 'contained remarkably little discussion of liability,' finding it initially denied in only $20 \%$ of cases. ${ }^{42}$ Most claims are of low value and not worth contesting and, as a result, insurers make at least some payment in the great majority of them. Only very rarely do they insist upon staging a gladiatorial contest to determine whether a particular defendant was in the wrong. Contrary to the impression gained from tort textbooks,

\footnotetext{
${ }^{41}$ S Lloyd-Bostock, Commonsense Morality and Accident Compensation in: DP Farrington et al (eds), Psychology, Law and Legal Processes (1979).

${ }^{42}$ Goriely/Moorhead/Abrams (fn 26) 103.
} 
duty of care, causation of damage, and even breach of duty are generally not in dispute in cases processed by the system.

Another element in establishing liability, at least in law student consciousness, is the importance of findings of law. Appeal cases are read one after another in order to distil the essence of what may be required to advise a client correctly and succeed in a claim. However, in practice, reference to the refined discussions of law which take place in the appellate courts rarely features in the everyday work of the personal injury practitioner. In road accident cases it has been shown that driving skills and common sense exercised within the scope of the 'rules of the road' are of much more importance than any legal principle. To emphasise this further, we can say that it is the facts rather than the law that are much more likely to determine the case. ${ }^{43}$ One barrister surveyed memorably commented that an excuse for not reading the papers for the case in detail in advance of a hearing was that the facts revealed in court would inevitably change:

You can only say how it looks on the evidence you have got at the initial stage, which is very rarely the picture that will emerge at the trial. There used to be a chap in these chambers whose motto was, 'Never mind about the law, it will all be decided on the facts, and never mind the facts because that will all have changed by the time your client comes out of the witness box anyway. ${ }^{44}$

\section{E. Tort cases reflect the justice requirements of due process and fairness}

As we have already seen the popular image of the delicately balanced scales of justice held by the goddess of justice needs close examination when it comes to considering what happens in the typical tort case. The right to representation and to control the way in which a claim is litigated have already been discussed. Here we consider further the factors that are influential in disposing of a claim and contrast them with the traditional portrayal of justice.

We have seen above that it is the facts found rather than the law in the books that are more important in determining the result of a claim. But how are those facts

\footnotetext{
${ }^{43}$ H Genn, Hard Bargaining (1987) 73.

${ }^{44}$ Ibid, 74.
} 
found? The traditional image is of a rigorous, impartial, and detailed investigation into what happened. In a road accident we might imagine there will be a careful forensic examination of the scene by experts in determining the cause of injury. The effects of speed, weather, the road surface and layout, vehicle design and so on will be carefully weighed. Witness statements from many potential parties will be taken and police reports will be scrutinised. Thereafter this evidence will be subject to cross examination in court to assess its probative value, this being done according to the strict rules of evidence. At each juncture the parties will be able to question and test the views put forward and submit their alternative views within the limits of the rules of civil procedure, which aim at providing a fair hearing for all.

The reality is very far from this idealised image. Classic empirical studies reveal that, in practice, it is insurance bureaucracy that largely dictates what facts are accepted, how the litigation proceeds, and whether, when, and for how much, claims are settled. ${ }^{45}$ Ross, in particular, found that the rules of tort were transformed when they came to be used in the system in three ways: firstly, they were simplified; secondly, they were made more liberal and thirdly, they were made more inequitable. ${ }^{46}$ Let us explain each of these features in turn, and reflect upon how the facts in most cases are actually found.

In practice, the rule that fault must be proven is too uncertain to apply to the individual circumstances of particular accidents. The rule has to be simplified and the facts found easily in order to process the claim. For reasons of cost and administrative efficiency, insurers have been forced to substitute other criteria for the theoretical tort analysis. Mechanical rules of thumb replace any detailed investigation into blame. For example, in practice the driver of the car that runs into the back of another is invariably found to be the one who is negligent. Similarly, the driver of the car emerging from the junction is the one presumed to be at fault for the ensuing

\footnotetext{
${ }^{45}$ See Genn (fn 43), Harris et al (fn 9) and, in the USA context, HL Ross, Settled Out of Court (1980). The major findings are supported by more recent empirical studies and, in particular, by Goriely/Moorhead/Abrams (fn 26). But see the critique of Genn's work in $R$ Dingwall et al, Firm Handling: The Litigation Strategies of Defence Lawyers in Personal Injury Cases (2000) 20 LS 1. ${ }^{46}$ Ross, ibid.
} 
collision. There is neither the time nor resources to instruct experts to analyse the scene of each road accident and precisely calculate the series of events leading to the accident: what really happened, what the parties did and might have done, receives little examination. Ross concludes: ${ }^{47}$ 'The price paid is reduction of any meaningful consideration of fault and the substitution of mechanical presumption for scientifically based investigation'.

Economic pressures mean that cases are disposed of on the basis of very limited paperwork alone, and this may bear only a limited relationship to what actually occurred. If a case gets to court it has been argued that the findings of fact are so uncertain that you might as well toss a coin to determine the result. ${ }^{48}$ Although these generalisations about how the facts are found and how litigation is conducted do not apply to all insurers for every type of case, ${ }^{49}$ they reveal that the basis upon which claims are decided is very different from the image of justice which emphasises due process considerations in determining what really happened.

One effect of these pressures upon insurers to dispose of cases efficiently is that the system is very much more liberal than it may appear. Ross revealed that many more claims succeeded than the strict rules of tort - emphasising the need to prove fault would allow. Often insurers pay something for claims which, if they were to be fully investigated, would be without legal foundation. As a result 'wherever there is insurance there is ... a closer approximation to the objectives of social insurance in fact than the doctrines of tort law would lead one to suppose. ${ }^{, 50}$

However, Ross also found that this liberality is but part of a system which overall is weighted in favour of insurers and results in much inequality. Indeed the case often used to illustrate the general inequalities in the legal system involves a 'one-shotter'

\footnotetext{
${ }^{47}$ Ibid, 100.

${ }^{48}$ Elliott/Street (fn 25) 243.

${ }^{49}$ Dingwall et al (2000) 20 LS 1.

${ }^{50}$ FV Harper/FG James, The Law of Torts (1956) s 13.7.
} 
accident victim suing a 'repeat player' insurer. ${ }^{51}$ Delay, uncertainty, financial need and other pressures cause claimants to accept sums much lower than a judge would award. The eagerness of claimants and their solicitors to get something from the system is reflected in the fact that, in the past, in two out of every three cases they accepted the very first formal offer made to them by the 'risk neutral' insurer. ${ }^{52}$ Those claimants who can withstand the pressures of litigation do better than those who cannot, with the result that those from a higher social class or wealthier background are more likely to succeed. ${ }^{53}$ Those who suffer most are the severely injured. Although in the greatest need, they will find their high value claim scrutinised in detail and processed very differently from the average case which typically involves but a minor upset and little, if any, financial loss. Those seriously injured are much less likely to receive 'full' compensation than those suffering minor injury. By contrast, the great majority of claimants quickly recover from their minor injury and, for a variety of reasons, are likely to emerge over-compensated for their economic loss. $^{54}$

The overall result of the settlement system is that rough and ready justice is dispensed, much influenced by insurance company personnel and procedures, and driven by the needs of the insurance industry and the cost of the legal process. The system produces arbitrary results and bears only a limited relationship to the portrayal of justice contained in the traditional tort textbook.

${ }^{51}$ The seminal article is $M$ Galanter, Why the 'Haves' Come out Ahead (1974) 9 Law and Society Review (L \& Soc Rev) 95. However, Dingwall et al (2000) 20 LS 1 emphasise that not all defendants in personal injury cases are 'repeat players', and they should not be treated as a homogenous group. Other limits of the article were examined in an anniversary special issue in (1999) 33 L \& Soc Rev 795.

${ }^{52}$ Harris et al (fn 9) table 3.3. Although a more recent study discloses more bargaining, almost a third of cases still settled after only one offer, and two thirds settled after two. Goriely/Moorhead/Abrams (fn 26) 154. Leech reports that her firm accepted only a quarter of the first offers made in 540 settled cases: C Leech, Better in than out, Law Society Gazette (LS Gaz) 10 (6 January 2005).

${ }^{53}$ Ross (fn 45).

${ }^{54}$ D Dewees/D Duff/M Trebilcock, Exploring the Domain of Accident Law: Taking the Facts Seriously (1996) 19. PA Bell/J O'Connell, Accidental Justice: The Dilemmas of Tort Law (1997) $63 \mathrm{ff.}$ 


\section{F. Tort focuses upon compensating financial loss and serious injuries}

One image of tort is of a caring system that compensates those who are especially needy when they are suddenly struck down by misfortune. Following a serious injury, the claimant may become very short of money. He may be unable to work. Sooner or later any support from his employer will be withdrawn and he may lose his job. Savings, if any, will run out and reliance only upon the meagre resources provided by the welfare state could prove difficult. He may be unable to support his family, the mortgage may not be paid and the home may then come under threat. The claimant's loved ones indirectly may then be among the sufferers. In addition, the claimant's injury may need continuing care. Certain medical equipment and rehabilitation treatment may not easily be obtained from the National Health Service and the cost of providing it privately can be very high. Without financial assistance, nursing support may be reduced to a minimum, recovery may be delayed, and pain increased. To relieve these financial concerns there is the tort system. One image of tort is thus that it is a system which provides direct financial support which is much needed by recipients of compensation who are seriously injured. Who could possibly question this basic humanitarian function of tort law and deny its efficacy?

Unfortunately the truth of the matter is again far removed from the picture that has just been painted. Firstly, it is not the case that damages in tort are predominately awarded to those who have been seriously injured and, secondly, financial loss comprises but a small part of the overall damages bill. Instead it is non-pecuniary loss that accounts for a disproportionate amount of damages. Pain and suffering and loss of amenity comprised two thirds of the total awarded thirty years ago, ${ }^{55}$ and it has remained at about that level.

The extraordinary importance given to pain and suffering, as opposed to financial loss, reflects the fact that most awards are for minor injury and involve relatively small sums. The average payment is less than $£ 5,000^{56}$ which is approximately two

\footnotetext{
${ }^{55}$ Pearson Commission (fn 6) vol 2 table 107.

${ }^{56}$ The median figure was $£ 2,500$ in the survey of 81,000 cases receiving legal aid and closed in 1996 97 in Pleasence (fn 35) 40 fig 3.17. P Fenn/N Rickman, Costs of Low Value Liability Claims 1997-
} 
month's average salary. In these minor cases claimants suffer very little, if any, loss of earnings and rarely incur medical costs. Future financial loss occurs in only $7 \%$ of cases and amounts to less than $9 \%$ of the total damages bill. ${ }^{57}$ Where road accidents are involved, $70 \%$ of the injuries in recent years have been attributed to the effects of whiplash. ${ }^{58}$ Claimants are then often left with symptoms which are difficult to disprove.

In practice, therefore, the claimants in tort who suffer catastrophic effects as a result of their accident are very unusual. Instead nearly all suffer very minor injuries and soon make a full recovery. They are not left with any continuing ill effects. In most cases the accident does not even result in a claim for social security benefits. ${ }^{59}$ It is these minor injury cases which account for the extraordinarily high costs of the system compared to the damages it pays out. ${ }^{60}$ But the essential point to note here is that the image of the tort system as caring for the immediate financial needs of mostly severely injured people in society is far from the reality.

\section{G. Tort awards full compensation for losses suffered}

2002 (2003), record average damages of only £3,000 for employers’ liability accident claims, although this study of almost 100,000 cases related only to claims for less than $£ 15,000$. See Department for Constitutional Affairs, <http://www.dca.gov.uk/majrep/claims/elclaims.htm>.

${ }^{57}$ Pearson Commission (fn 6) vol $2 \S 44$ and table 107. However, ten years ago the Association of British Insurers estimated that $46 \%$ of the value of claims between $£ 100,000$ and $£ 250,000$ comprised future loss: Lord Chancellor's Department, Courts Bill: Regulatory Impact Assessment (November 2002) table 8.

${ }^{58}$ House of Commons Transport Committee, The Cost of Motor Insurance, Fourth Report of Session 2010-11 vol $1 \quad$ (HC 591) $\quad \S 16, \quad$ available online at <http://www.publications.parliament.uk/pa/cm201011/cmselect/cmtran/591/59105.htm >

${ }^{59}$ The Compensation Recovery Unit issues a nil certificate in $70 \%$ of the cases where a compensator intends to make a payment. See $R$ Lewis, Deducting Benefits from Damages for Personal Injury (1999) $§ 14.05$.

${ }^{60}$ The figures always bear repetition. The Pearson Commission estimated that the cost of operating the tort system amounted to $85 \%$ of the value of tort payments distributed to claimants. See Pearson Commission (fn 6) vol 1 § 256. The Lord Chancellor's Civil Justice Review (Cm 394, 1988) estimated that the cost of the tort system consumed $50-70 \%$ of the total compensation awarded in personal injury cases. 
Although most injuries compensated by tort are minor a few are much more serious and account for a substantial amount of the damages paid. In 2002 insurers estimated that only $1 \%$ of all cases in the tort system resulted in a payment of $£ 100,000$ or more. However, these few cases were responsible for $32 \%$ of the total damages paid out by the system. ${ }^{61}$ It is these serious injuries that are more likely to come to public attention partly because they are more likely to go to court and be reported in newspapers. These accounts in the press are often written so as to suggest that the damages award is akin to a very large pools win. They may even give rise to feelings of envy in the reader because of the amount of the 'windfall'. What is rarely explored is the suffering and loss of the victim and how his day-to-day life has dramatically changed. The newspapers only rarely couple the compensation paid with details of the problems faced by those who have suffered, for example, spinal injury or brain damage. Instead the impression that is often left is that these tragic victims are exceptionally well cared for by society and that many of them are among the growing number of new millionaires.

It is certainly true that the recipients of tort damages are much better treated than the majority of accident victims for the latter are left to rely upon their own resources as supplemented by the safety net of the welfare state. ${ }^{62}$ However, it is misleading to suggest that victims of serious injury will have all their needs met by the tort system. Compensation has traditionally been awarded in the form of a lump sum and the experience of past decades has proven that, for those who need long term care and support, it will prove insufficient. There are many reasons for this.

One major factor for the erosion of the lump sum is that in its calculation too little allowance is made for of the effects of inflation. A discount rate is used to allow for the fact that the claimant will receive compensation earlier than he would have had he been able to work for the wages now lost. This rate has consistently been set too

${ }^{61}$ Lord Chancellor's Department, Courts Bill: Regulatory Impact Assessment (November 2002) table 1.

${ }^{62}$ Even where an accident causes incapacity for work for six months or more only a third of victims receive tort damages: Pearson Commission (fn 6) vol 1 table 5. 
low; it has never matched the true rate of return on investment that the claimant can actually achieve. ${ }^{63}$ At present a claimant is expected to achieve a real rate of return above inflation and after taxation of $2.5 \%$. With inflation at $3.5 \%$ and taxation costs at a further $1 \%$, the claimant must obtain a return of $7 \%$ at a time when the bank rate is as low as $0.5 \%$. It is inevitable that any lump sum awarded will be eroded much more quickly than the court presumed.

Nor have courts made enough allowance for the substantial increase in life expectancy that is now evident. In contrast, too much allowance has been made for the prospective potential earning capacity of the disabled person. ${ }^{64}$ All this is likely to result in the money proving insufficient in the long term. A final reason for undercompensation is that the lump sum is likely to be agreed out of court and, because of the uncertainties of litigation, will reflect a substantial discount from what a judge would award. A sum less than the actual loss suffered is thus often accepted. For a variety of reasons, therefore, claimants are unlikely to receive 'full' compensation and in practice are not returned to the position they were in before the accident.

\section{Tort and the modern portrayal of a compensation culture}

\section{A. The 'Compensation Culture'}

Competing with the idealised (and often misleading) images of tort law considered in the above section is the widespread perception that tort has contributed to a damaging 'compensation culture' ${ }^{65}$ Our propensity to claim is thought to have increased to such

${ }^{63}$ As noted in an introduction to the Government Actuary's Department, Actuarial Tables for Use in Personal Injury and Fatal Accident Cases (5th edn 2004) $§ 15$, the set discount rate has never been within $0.5 \%$ of the correct rate of return. The effect of this is illustrated in the introduction to $R d e$ Wilde et al, Facts and Figures (13th edn 2009). To achieve full compensation a discount rate of at most $1 \%$ and not $2.5 \%$ should be applied. This would substantially increase lump sum payments.

${ }^{64}$ R Lewis/R McNabb/V Wass, Court Awards of Damages for Loss of Future Earnings: An Empirical Study and an Alternative Method of Calculation (2002) 29 Journal of Law \& Society (J Law \& Soc) 406 and [2002] JPIL 151.

${ }^{65}$ On the compensation culture generally, see $K$ Williams, State of Fear: Britain's 'Compensation Culture’ Reviewed (2005) 25 LS 499; R Lewis/A Morris/K Oliphant, Tort Personal Injury Statistics: 
an extent that we are now seeking personal injury compensation on a routine basis regardless of fault. The media regales us with entertaining but worrying tales of claims for pure accidents and for trivial injuries. Spurious and fraudulent claims are thought to be commonplace though complaints are also levelled at legitimate claims. Increased claiming is thought to represent a decline in stoicism and personal responsibility. As such, claimants are depicted not as the victims of wrongdoing but as 'scroungers"' ${ }^{66}$ and 'self-pitying milksops'. ${ }^{67}$ For some, this state of affairs is thought to stem from longer-term developments within tort law, namely the expansion of tortious liability and the dilution of the fault principle to which the British are culturally tied. ${ }^{68}$ Concerns about the compensation culture are more frequently associated, however, with shorter-term developments within the tort system since the 1990s: the emergence of widespread claims advertising and direct marketing; the introduction of 'no-win no-fee' agreements; and the practice of paying for the referral of claims.

In the 1970s, personal injury claims were handled by general practice solicitors who waited passively for clients' instructions. By the late 1990s, however, personal injury had become a specialist area of practice and lawyers were advertising for work. ${ }^{69}$

Is There a Compensation Culture in the UK? (2006) 14 Torts Law Journal (TLJ) 158; $R$ Mullender, Negligence Law and Blame Culture: A Critical Response to a Possible Problem (2006) 22 Professional Negligence (PN) 2; A Morris, Spiralling or Stabilising? The Compensation Culture and our Propensity to Claim Damages for Personal Injury (2007) 70 MLR 349 and J Hand, The Compensation Culture: Cliché or Cause for Concern? (2010) 37 J Law \& Soc 569.

${ }^{66}$ P Broster, War on the scroungers (The Express, 29 November 2004).

${ }^{67} P$ Toynbee, A compensation culture makes victims of us all (The Guardian, 21 April 1999).

${ }^{68}$ Atiyah (fn 6); F Furedi, Courting Mistrust: The Hidden Growth of the Culture of Litigation in Britain (1999); D Lloyd, The Compensation Culture: A New Legal Paternalism?, in: E Lee (ed), Compensation Crazy: Do we Blame and Claim Too Much? (2002) 49. C Harlow, State Liability: Tort Liability and Beyond (2004).

${ }^{69}$ For further information on the development of the personal injury claims market, see $R$ Abel, English Lawyers between Market and State: The Politics of Professionalism (2003) and H Kritzer, The Fracturing Legal Profession: The Case of Plaintiffs' Personal Injury Lawyers (2001) 8 International Journal of the Legal Profession 225. 
Seeing the potential in the market, claims management companies (CMCs) emerged. ${ }^{70}$ CMCs realised that they could make money by recruiting clients and selling them on to lawyers. They engaged in mass claims advertising on television, on the radio, in newspapers and on billboards. They also made direct approaches to people on the streets, in housing estates and outside schools. ${ }^{71}$ Some even offered financial inducements to claim. Solicitors' conduct rules which prevented them from paying CMCs for the referral of claims were flouted on a regular basis and so the ban on such payments was lifted in $2004 .^{72}$ In response to concerns about unethical practices, the government began to regulate the operation of CMCs in $2007 .{ }^{73}$ Whilst such companies can no longer make direct approaches in person, they have adapted by sending unsolicited text messages and making unsolicited phone calls. ${ }^{74}$ There are now 2,500 CMCs registered for personal injury work. The market in claims has become big business with lawyers commonly paying between $£ 600$ and $£ 900$ for each

${ }^{70}$ See further Boleat Consulting, The Claims Standards Council (December 2005).

${ }^{71}$ National Association of Citizens Advice Bureaux, Door to Door: CAB Clients' Experiences of Doorstep Selling (September 2002).

${ }^{72}$ P Rohan, Law Society Votes to Allow Referral Fees,, LS Gaz 9 January 2004. On referral fees, see further: Vanilla Research, Referral Arrangements Research (2010); Charles River Associates, Cost Benefit Analysis of Policy Options Related to Referral Fees in Legal Services (2010); Legal Services Board, Referral Fees, Referral Arrangements and Fee Sharing: Decision Document (2011); A Higgins, Referral Fees - The Business of Access to Justice (2012) 32 LS 109.

${ }^{73}$ In accordance with sec 4 of the Compensation Act 2006, those wishing to offer claims management services must first obtain authorisation from the regulator, unless exempt or subject to a waiver. The details of the authorisation process are contained in the Compensation (Claims Management Services) Regulations 2006, SI 2006/3322. Once authorised, CMCs must comply with a code of conduct: Conduct of Authorised Persons Rules 2006. On a general level, this requires CMCs to conduct themselves honestly, responsibly and with integrity. More specifically, the code seeks to control the way in which CMCs advertise and market their services.

${ }^{74}$ M Boleat, Claims Management Regulation: Impact of Regulation Third Year Assessment (2010); Ministry of Justice, Claims Management Regulation Annual Report 2010/2011 (2011). Lord Young of Graffham has raised concerns about the inadequacy of claims management regulation: Common Sense Common Safety (2010). 
referral. Personal injury claims are now big business and lawyers commonly pay between $£ 600$ and $£ 900$ even for lower value claims. ${ }^{75}$

This growth in claims advertising, CMCs and payments for referrals was fuelled by the privatisation of funding for personal injury claims in 2000. Legal aid was largely abolished and the use of conditional fee agreements (CFAs) was expanded. ${ }^{76}$ Under these agreements claimant lawyers could secure an increase in their fees in each case that they won. They could recover up to double their costs if they were successful but nothing at all if they lost. ${ }^{77}$ Claimants themselves were encouraged to litigate under these 'no-win no-fee' deals because the only financial risk to which they were exposed was liability for the defendant's costs if the case was lost. Even though in most cases this risk was only remote, further protection was at hand: for a suitable premium, insurance could be arranged so as to relieve the claimant of any concern over funding his claim. Damages could thus be sought at no financial risk to the claimant. It is widely perceived that this gave claimants no reason not to 'have a go'. ${ }^{78}$ As such, tort is thought to have become a moral hazard.

${ }^{75}$ R Jackson, Review of Civil Litigation Costs: Final Report (January 2010) § 3.18. Section 56 of the Legal Aid, Sentencing and Punishment of Offenders Act 2012 seeks to prevent payments for referrals though it is generally acknowledged that the claims market will find ways in which to circumvent the ban: J Hyde, New Claims Company Aims High, LS Gaz (17 November 2011) 1.

${ }^{76}$ Sections 27 and 29 of the Access to Justice Act 1999. See further, R Moorhead, Conditional Fee Agreements, Legal Aid and Access to Justice (1999) 33 University of British Columbia Law Review (UBC L Rev) 471 and $R$ Abel, An American Hamburger Stand in St Paul's Cathedral: Replacing Legal Aid with Conditional Fees in English Personal Injury Litigation (2001) 51 DePaul Law Review (DePaul L Rev) 253.

${ }^{77}$ In practice in nine out of ten personal injury cases the uplift in fees is limited by industry wide agreements. In road traffic accidents it is generally restricted to $12.5 \%$, in employment accident cases to $25 \%$ and in employment disease cases to $27.5 \%$. See Civil Procedure Rules, Part 45 secs III, IV and VG Wignall (ed), Conditional Fees, A Guide to CFAs and Litigation Funding (2008).

${ }^{78}$ In response to such concerns, sec 44 of the Legal Aid, Sentencing and Punishment of Offenders Act 2012 will make claimants liable to pay the uplift in fees out of their damages. They will still, however, be able to initiate a claim without incurring any expense. 
The unrestrained culture of claiming thought to have stemmed from these developments has led to widespread concerns that tort has become a burden which is undermining rather than underpinning society. Organisations, businesses, public bodies and individuals are said to have become increasingly risk averse for fear of being sued. The papers carry stories of teachers refusing to take children on school trips, councils felling trees and volunteering in decline. Mounting claims are also thought to have affected the availability and affordability of liability insurance. The compensation culture is said to be "plundering the UK economy" ${ }^{, 79}$ and "cutting a swathe through public service budgets' ${ }^{80}$ As such, in stark contrast to the traditional portrayal, the modern image of tort is very critical. In common with the traditional portrayal, however, we can point to a dissonance between perceptions of tort in culture and the reality in practice.

\section{B. Trends in our propensity to claim personal injury compensation}

\section{Overview}

Whilst historical data are in short supply, those which are available support the view that there has been a long-term increase in the number of personal injury claims. They appear to have arisen four-fold since the 1970s. The Pearson Commission estimated that there were 250,000 claims in $1973 .{ }^{81}$ In 1988 , the Civil Justice Review estimated that there were around 340,000 claims. ${ }^{82}$ In 2011/2002, the Compensation Recovery Unit (CRU) recorded just over one million claims. ${ }^{83}$ Established in 1989, CRU administers the recovery of social security benefits from tort damages and holds reliable data on the number of claims pursued, whether successful or unsuccessful, settled or litigated. ${ }^{84}$ Unfortunately, CRU's data has only been publicly available

\footnotetext{
${ }^{79}$ Blame culture is the road to suicide (Daily Telegraph, 3 February 2004).

${ }^{80}$ Dead budgies and muddy boots cost us a fortune (The Times, 15 July 2003).

${ }^{81}$ Pearson Commission (fn 6) vol $2 \S 59$.

${ }^{82}$ Civil Justice Review (fn 60), 391.

${ }^{83}$ The CRU statistics are available at <http://www.dwp.gov.uk/other-specialists/compensationrecovery-unit/performance-and-statistics/>.

${ }^{84}$ All compensators, including self-insurers, are required to report details of the claims they receive to the Unit, in accordance with the Social Security (Recovery of Benefits) Act 1997. As such, the
} 
since 2000 though data are available for $1997 / 1998{ }^{85}$ As such, it is not possible to track the impact of increasing claims advertising through the 1990s though it is possible to see the impact of the removal of legal aid and the expansion of CFAs in 2000 and the increasing practice of paying for the referral of claims.

Table 1: Personal injury claims per year (various sources)

\begin{tabular}{|l|c|l|l|}
\hline Year & Number of claims & Year & Number of claims \\
\hline 1973 (estimate) & 250,000 & & \\
\hline 1988 (estimate) & 340,000 & $2005 / 2006$ & 674,422 \\
\hline $1997 / 1998$ & 705,232 & $2006 / 2007$ & 710,784 \\
\hline $2000 / 2001$ & 735,931 & $2007 / 2008$ & 732,750 \\
\hline $2001 / 2002$ & 688,315 & $2008 / 2009$ & 812,348 \\
\hline $2002 / 2003$ & 706,697 & $2009 / 2010$ & 861,325 \\
\hline $2003 / 2004$ & 770,243 & $2010 / 2011$ & 987,381 \\
\hline $2004 / 2005$ & 775,875 & $2011 / 2012$ & $1,041,150$ \\
\hline
\end{tabular}

There may have been a significant increase in claims during the 1990s which levelled off in the 2000s, though the limited data available for 1997/1998 does not support this. Nevertheless, it is clear that between 2000 and 2006 when the media, politicians and representative groups were bemoaning our ever-increasing propensity to claim, the number of claims was relatively stable. In fact, the number of accident, as opposed to disease, claims actually declined between 2003 and $2005{ }^{86}$ It is true, however, that

number of claims notified to CRU each year should largely equate with the number of personal injury claims being pursued.

${ }^{85}$ These data were uncovered by Richard Lewis during his research for Deducting Benefits from Damages for Personal Injury (fn 59) and are derived from an internal memorandum of the Department of Social Security.

${ }^{86}$ The figures from CRU for accident claims are as follows: 2000/2001 (612,120), 2001/2002 $(614,126), 2002 / 2003(615,546) 2003 / 2004(557,186), 2004 / 2005(579,282)$ and 2005/2006 $(629,981)$. 
claims have increased annually since 2006 though it is misleading to talk about general trends in our propensity to claim as trends differ in accordance with the type of claim.

\section{Clinical negligence}

As can be seen from the table below, the number of clinical negligence claims has increased significantly since the Pearson Commission's estimate in 1973.

Table 2: Clinical negligence claims per year (various sources)

\begin{tabular}{|l|c|l|c|}
\hline Year & Number of claims & Year & Number of claims \\
\hline 1973 (estimate) & 700 & $2006 / 2007$ & 8,575 \\
\hline $2000 / 2001$ & 10,901 & $2007 / 2008$ & 8,876 \\
\hline $2001 / 2002$ & 9,779 & $2008 / 2009$ & 9,880 \\
\hline $2002 / 2003$ & 7,977 & $2009 / 2010$ & 10,308 \\
\hline $2003 / 2004$ & 7,121 & $2010 / 2011$ & 13,022 \\
\hline $2004 / 2005$ & 7,205 & $2011 / 2012$ & 13,517 \\
\hline $2005 / 2006$ & 9,321 & & \\
\hline
\end{tabular}

Between 2000 and 2010, however, the number of such claims fluctuated though there has been a significant increase in the past two years. Nevertheless, clinical negligence claims constitute only $1 \%$ of all personal injury claims. Moreover, there does not appear to be a strong culture of claiming in this context. The Department of Health has suggested that there are in the region of 850,000 'adverse events' annually in the National Health Service, half of which may be avoidable. ${ }^{87}$ Whilst a crude measure, this suggests that only $3 \%$ of people with grounds for complaint go on to pursue a claim.

${ }^{87}$ Department of Health, An Organisation with a Memory: Report of an Expert Group on Learning from Adverse Events in the NHS (2000). 


\section{Public liability}

The Pearson Commission did not estimate the number of public liability claims though; at most, they stood at $28,000 .^{88}$

Table 3: Public liability claims per year (various sources)

\begin{tabular}{|l|c|l|c|}
\hline Year & Number of claims & Year & Number of claims \\
\hline 1973 (estimate) & $<28,000$ & $2006 / 2007$ & 79,841 \\
\hline $2000 / 2001$ & 95,883 & $2007 / 2008$ & 79,472 \\
\hline $2001 / 2002$ & 100,989 & $2008 / 2009$ & 86,164 \\
\hline $2002 / 2003$ & 109,782 & $2009 / 2010$ & 91,052 \\
\hline $2003 / 2004$ & 91,453 & $2010 / 2011$ & 94,872 \\
\hline $2004 / 2005$ & 87,247 & $2011 / 2012$ & 104,863 \\
\hline $2005 / 2006$ & 81,615 & & \\
\hline & & & \\
\hline
\end{tabular}

Again, therefore, whilst there has been a significant increase in the long-term, in the short-term the number of such claims has fluctuated. It is difficult to capture data on the potential number of claims in this context as compared with the actual number of claims. Government data indicates, however, that in 2002 there were over 5 million home and leisure accidents that caused a serious enough injury to warrant a visit to hospital. ${ }^{89}$ This includes approximately 520,000 accidents on an urban road, street or

${ }^{88}$ The Pearson Commission estimated that there were 28,000 personal injury claims 'other' than road traffic accident, employers' liability and clinical negligence claims. This included personal injury claims in the following categories: products and services (excluding medical services), occupiers' liability claims and 'other'. See Pearson Commission (fn 6) vol 2 table 11.

${ }^{89}$ These data estimates are derived from the Home Accident Surveillance System (HASS) and Leisure Accident Surveillance System (LASS) run by the Department of Industry, both of which closed in 2003. The data are now available from the Royal Society for the Prevention of Accidents: <http://www.hassandlass.org.uk/query/reports.htm>. 
pavement (excluding road traffic accidents), 58,000 accidents in a shopping area, 22,500 accidents in business or leisure public buildings, 244,500 accidents in schools, 38,000 in public playgrounds and 44,000 accidents in public houses. Whilst it is impossible to estimate the number of such accidents involving an element of negligence, it is clear that the number of accidents occurring in public spaces is very much larger than the number of public liability claims.

\section{Employers' liability (accident and disease)}

Between 2000 and 2005, the number of employers' liability claims fluctuated considerably. This was largely due to trends in disease claims and the establishment in 1999 of a temporary special scheme of compensation for respiratory diseases. This scheme closed in 2004 and since then the number of employers' liability claims has fallen each year.

Table 4: Employers' liability claims per year (various sources)

\begin{tabular}{|l|c|l|c|}
\hline Year & Number of claims & \multicolumn{1}{|c|}{ Year } & Number of claims \\
\hline 1973 (estimate) & 117,600 & $2006 / 2007$ & 98,478 \\
\hline $2000 / 2001$ & 219,183 & $2007 / 2008$ & 87,198 \\
\hline $2001 / 2002$ & 170,554 & $2008 / 2009$ & 86,957 \\
\hline $2002 / 2003$ & 183,342 & $2009 / 2010$ & 78,744 \\
\hline $2003 / 2004$ & 291,210 & $2010 / 2011$ & 81,470 \\
\hline $2004 / 2005$ & 253,502 & $2011 / 2012$ & 87,350 \\
\hline $2005 / 2006$ & 118,692 & & \\
\hline
\end{tabular}

Whilst there was an increase in claims in 2011/2012, there are still fewer employers' liability claims today than in 1973. Whilst arguably this accords with increased health and safety at work, the Health and Safety Executive (HSE) states that in 2010/2011 115,379 injuries resulting in three or more days off work were reported by employers and 1.2 million working people suffered from a work-related illness, half a million of 
which arose that year. ${ }^{90}$ On the basis of HSE statistics, the Trade Union Congress estimates that only one in ten people injured at work go on to claim compensation. ${ }^{91}$

\section{The dissonance between the modern image of tort and reality}

A dissonance has arisen between the modern image of tort and reality in several respects. Firstly, whilst there has been a moderate long term increase in the number of clinical negligence, public liability and employers' liability claims, this increase has not been sustained in the employers' liability context. There were fewer employers' liability claims in $2010 / 2011$ than in 1973. Secondly, the perception that claims advertising, 'no-win no-fee' agreements and payments for referrals have led to increasing numbers of claims since the late 1990s is misplaced. In view of the number of accidents that could lead to claims, the culture of claiming in the UK is relatively weak in the clinical, employment and public context. Thirdly, the notion that we are more willing to claim for trivial injuries than in the past is unsupported by evidence. As outlined above (section I.F), although it is true that the majority of claims involve minor injuries with a value of less than $£ 5,000$, this has long been the case. ${ }^{92}$ Fourthly, concerns that spurious claims are commonplace are exaggerated. Inevitably there are spurious and fraudulent claims within the system. There have been particular concerns in respect of public liability claims. In a 2004 survey, $68 \%$ of councils reported an increase in the number of tenuous and fraudulent claims for compensation. ${ }^{93}$ Such evidence is anecdotal, however, and the extent of spurious claiming remains unclear. Claims have not increased substantially since 2000 and this implies that developments within the tort system have not led to widespread spurious claiming.

\footnotetext{
$90<$ http://www.hse.gov.uk/statistics/>.

${ }^{91} S$ Pickvance, A Little Compensation (2005) Hazards, <www.hazards.org/compensation/alittlecompensation.pdf $>$.

${ }^{92}$ Above section 1E.

${ }^{93}$ Local Government Association, Suing the Council - Helping the Citizen or Harming the Community (2004).
} 
Fifthly, in light of this, it is difficult to support complaints that tort in recent years has become a burden as a result of increasing numbers of claims (as opposed to the increasing cost of claims). ${ }^{94}$ Indeed a government review found that complaints about the availability and affordability of employers' liability insurance had been exaggerated in the media and that increases in premiums that had occurred were due to non-tort related factors, including the under-pricing of insurance, a fall in investment income and the increasing cost of reinsurance following the terrorist attacks on 11 September $2001 .^{95}$ In addition, the extent of risk aversion appears to have been exaggerated and stems to a large extent from perceptions surrounding tort practice rather than tort practice itself. ${ }^{96}$ Finally, complaints that claiming represents a decline in personal responsibility choose to privilege anecdotal critical accounts: long-term increases in claiming could equally be presented as a desirable increase in access to justice and defendant accountability.

The fact that recent developments within the tort system have not increased levels of claiming is certainly surprising. Felstiner et al explain that claims are socially constructed through a process of naming, blaming and claiming. ${ }^{97}$ In accordance with this process, an individual transforms an unperceived injurious experience into a perceived injurious experience (names); attributes that injurious experience to the

${ }^{94}$ For an assessment of compensation culture and its impact, see further Better Regulation Task Force, Better Routes to Redress (2004) and House of Commons Constitutional Affairs Committee, Compensation Culture, Third Report (HC 754-I, 2005). Concerns about the cost of resolving claims have more foundation and have attracted significant political attention. See further A Morris, The Compensation Culture and the Politics of Tort, in: J Steele/TT Arvind (eds), Tort and the Legislature: Common Law, Statute and the Dynamics of Legal Change (forthcoming).

${ }^{95}$ Department for Work and Pensions, Review of Employers' Liability Compulsory Insurance, First Stage Report (2003).

${ }^{96}$ For example, Williams has reported that Bury St Edmunds won a 'Flowers in Bloom' award despite reports that its council was taking down its hanging baskets for fear of being sued: K Williams, Politics, the Media and Refining the Notion of Fault: Section 1 of the Compensation Act 2006 [2006] JPIL 347.

${ }^{97}$ W Felstiner/R Abel/A Sarat, The Emergence and Transformation of Disputes: Naming, Blaming and Claiming (1981) 15 L \& Soc Rev 631. 
fault of another individual or entity (blames) and then voices that grievance to the person or entity believed to be responsible (claims). The authors stress that each stage of the transformation is 'subjective, unstable, reactive, complicated and incomplete'. 98 Individuals name, blame and claim by perceiving, interpreting and reacting to circumstances and events in particular ways and a wide variety of factors will affect an individual's response to injury. ${ }^{99}$ Moreover, to move through this naming, blaming and claiming process, the injured must be able and willing to do so, which will not always be the case. Individuals may, therefore, name but not blame or blame but not claim. Levels of claiming depend, therefore, on the prevalence of external factors and conditions which affect our ability and willingness to transform injuries into claims. It also depends on our legal consciousness which shapes our perceptions of our ability to claim and informs our willingness to do so.

Research has demonstrated that, in the past, potential claimants were unable to claim because they were not aware they could do so or did not know how. ${ }^{100}$ In addition, their willingness to claim was dampened by both concerns that claiming would be stressful, expensive and intimidating and by doubts about the utility of claiming. ${ }^{101}$ We would expect widespread 'no-win no-fee' advertising, fuelled by payments for referrals, to change this. ${ }^{102}$ Most obviously, advertising raises our awareness not only

${ }^{98}$ Ibid, 637.

${ }^{99} M$ Galanter, Reading the Landscape of Disputes: What we Know and Don't Know (And Think we Know) About Our Allegedly Contentious and Litigious Society (1983) 31 University of California at Los Angeles Law Review (UCLA L Rev) 4, 61.

${ }^{100}$ Many injured people did not claim in the past because they did not know that they had a claim or did not know how to pursue it: Harris et al (fn 9) $65 \mathrm{ff}$.

${ }^{101}$ One survey found that one of the most important reasons for not claiming was an inability or unwillingness to undergo the possible trouble or bother of making a claim' and there was 'considerable reluctance to become involved in the strains of a legal claim': Harris et al (fn 9) 71. Fear of legal costs was another significant reason for not claiming. $11 \%$ of respondents who had considered the possibility of claiming damages cited fear of legal costs as a reason for not going ahead: Harris et al (fn 9) 71 ff. See also Genn (fn 43) 50.

${ }^{102}$ See further Morris (2007) 70 MLR 349, 372 ff; A Morris, Claims Advertising: Access or Excess? (2005) 155 NLJ 345. On general attitudes to claims advertising, see Millward Brown, Effects of Advertising in Respect of Compensation Claims for Personal Injury (2006). 
of the possibility of claiming after an accident but also of how to claim. Advertising also seeks to increase our willingness to claim in several ways. Firstly, it may reduce concerns we have about claiming and seeking legal advice. The public are able to receive anonymous advice through phone lines, thereby removing the fear of dealing with lawyers face-to-face. Adverts convey the impression that claiming is quick, easy and stress-free by avoiding images of judges and court scenes. The claims process is portrayed as routine, depersonalised and administrative rather than adversarial in nature. In addition, using the 'no-win no-fee' tagline, adverts seek to reassure the public that it will be both free and easy to obtain legal advice and representation. Secondly, adverts seek to reinforce the utility of claiming. They give examples of compensation awarded for various injuries sustained in different contexts, thereby highlighting the financial worth of pursuing a claim. They also imply that claims are frequently successful. Finally, adverts seek to create a sense of entitlement and talk of 'rights' to compensation. ${ }^{103}$

Nevertheless, claim rates remain low for most injuries. It is not clear from the limited data available whether claims advertising has not been effective in increasing our general ability and willingness to claim or whether it has been effective in encouraging us to seek legal advice but that levels of claiming are being restrained by lawyers on economic grounds. Whilst CFAs may remove the financial risk of claiming from claimants, they transfer that risk to the lawyer. Lawyers working on a 'no-win no-fee' basis must have sufficient resources to invest in a claim until its conclusion and take the risk of not getting paid if the claim fails. There is some evidence of CFA lawyers screening out economically unattractive claims as a result, although our knowledge and understanding of CFA practice is limited. ${ }^{104}$

\footnotetext{
${ }^{103}$ Markesinis suggests that feelings of entitlement are one reason for the higher rates of claiming in the United States compared with the UK: B Markesinis, Litigation-Mania in England, Germany and the USA: Are we so Very Different? (1999) 49 Cambridge Law Journal (CLJ) 233, 254.

${ }^{104}$ See further $P$ Fenn/A Gray/N Rickman, The Impact of Conditional Fees on the Selection, Handling and Outcome of Personal Injury Cases (2002); P Fenn/A Gray/N Rickman, The Impact of Sources of Finance on Personal Injury Litigation (2002); $R$ White/R Atkinson, Personal Injury Litigation, Conditional Fees and After-the-Event Insurance (2000) 19 Civil Justice Quarterly (CJQ) 118.
} 


\section{The exception in relation to road traffic accidents}

In stark contrast to other types of claim, there has been both a long-term and shortterm increase in the number of road traffic accident (RTA) claims involving personal injury.

Table 5: Road traffic accident claims per year (various sources)

\begin{tabular}{|l|c|l|c|}
\hline Year & Number of claims & Year & Number of claims \\
\hline 1973 (estimate) & 103,300 & $2006 / 2007$ & 518,821 \\
\hline $2000 / 2001$ & 401,757 & $2007 / 2008$ & 551,905 \\
\hline $2001 / 2002$ & 400,445 & $2008 / 2009$ & 625,072 \\
\hline $2002 / 2003$ & 398,892 & $2009 / 2010$ & 674,997 \\
\hline $2003 / 2004$ & 374,761 & $2010 / 2011$ & 790,999 \\
\hline $2004 / 2005$ & 402,924 & $2011 / 2012$ & 828,489 \\
\hline $2005 / 2006$ & 460,097 & & \\
\hline
\end{tabular}

Between 2000 and 2004 the number of RTA claims actually declined but since 2004 it has increased each year with the result that over the last six years the total has doubled. This increase is largely responsible for the long-term increase in all personal injury claims. In 1973, RTA claims constituted $41 \%$ of all personal injury claims. By 2000/2001, this had increased to 54\% and by 2011/2012 RTA claims constituted $80 \%$ of all claims. This increase has occurred despite the fact that the number of casualties (deaths and injuries) on the road reported to the police is falling: only 222,146 road casualties were reported to the police in 2009 , being far below the number of claims pursued that year. ${ }^{105}$ The Department for Transport acknowledges, however, that not all casualties are reported to the police and estimates that the actual number of road

\footnotetext{
${ }^{105}$ These statistics are published on the Department for Transport website at: <http://www.dft.gov.uk/statistics/series/road-accidents-and-safety/>.
} 
casualties each year stands at 730,000. ${ }^{106}$ This still indicates, however, that a large majority of people injured in RTAs go on to claim compensation. There is clearly a strong culture of claiming in this context.

Whilst there has been some exaggeration, it is generally accepted that the increased number of RTA claims in recent years is causing problems with the affordability and availability of car insurance. ${ }^{107}$ In addition, concerns surrounding the quality of RTA claims appear to have a stronger foundation. It seems that the increase in claims is largely attributable to an increase in whiplash claims, which reportedly constitute $70 \%$ of all claims. ${ }^{108}$ By 2004, the UK already had twice the average number of whiplash claims compared with other European countries and since then the number of RTA claims has doubled. ${ }^{109}$ Whiplash injuries can result in chronic disability though many whiplash claims involve only trivial injuries from low-impact collisions and result in only short periods of severe pain, require no medical treatment and result in no absence from work. ${ }^{110}$ Whilst data are in short supply, it does seem that we are more likely to claim for a trivial injury after an RTA than in other contexts.

In addition, it also appears we are more likely to engage in fraud in the RTA context. The problem is that whiplash may be established in many cases on the basis of a medical report which simply confirms that somebody has reported pain after an

${ }^{106}$ Department for Transport, Reported Road Casualties in Great Britain: 2010 Annual Report (2011).

${ }^{107}$ House of Commons Transport Committee (2011) (fn 58) and Cost of Motor Insurance: Follow Up, Twelfth Report (HC 1451, 2012). See also Office of Fair Trading, Private Motor Insurance: Summary of Responses to the OFT's Call for Evidence (OFT 1397, 2011).

${ }^{108}$ House of Commons Transport Committee (2011) (fn 58) § 16. See also Association of British Insurers, Tackling Whiplash: Prevention, Care and Compensation (2008).

${ }^{109}$ European Insurance and Reinsurance Federation (CEA), Minor Cervical Trauma Claims (2004) 4.

${ }^{110}$ Recent examples include Pollit v O'Dell (1 February 2011) where Salford County Court awarded $£ 1200$ to a 42 year old male for a whiplash injury. The symptoms were at their most severe for two weeks but nominal for most of the three month recovery period. The claimant self-medicated with pain relief and was not absent from work. See also, John v Chan (23 November 2010) where the 40year-old claimant recovered $£ 1,500$ for his whiplash injury. He made a full recovery within four months though by six weeks his symptoms were occasional. Again, he self-medicated and took no time off work. Both cases are reported in Current Law Monthly Digest: April [2012] 4 C.L. 85. 
accident. Whilst many whiplash claims will be genuine there is evidence of organised criminals staging or inducing collisions. The Insurance Fraud Bureau estimates that there were 30,000 staged accidents in 2009. ${ }^{111}$ Given the non-demonstrable nature of the injury, there are also understandable concerns about opportunistic fraud, that is, where there has been an accident but the claimant pretends to have suffered from whiplash or exaggerates the symptoms. There are also instances of so-called 'phantom passengers' pretending to have been injured in a car or bus that has been involved in an accident. ${ }^{112}$ Whilst there is much disagreement about the extent of the problem even claimant representatives have expressed their concern. ${ }^{113}$

This analysis raises a number of questions. Given we are all exposed to the same 'nowin no-fee' advertising and the same funding mechanisms are available for RTAs as for other types of claim, why has such a strong culture of claiming developed after an RTA so that such claims have come to dominate the tort system? Why do we appear to be more likely to pursue trivial and/or fraudulent claims in this context? In the first part of this article, we explained how compulsory insurance has influenced the types of claims pursued within the tort system but why have RTA claims increased significantly when employers' liability claims have not?

Traditionally, one of the reasons why people were more likely to claim after an accident at work or on the road than in other contexts was because they were much more likely to come into contact with someone who advised them of the possibility of claiming. ${ }^{114}$ Whilst in the case of work accidents this advice usually came from a

${ }^{111}$ House of Commons Transport Committee (fn 58) 17. A number of those involved in such 'crash for cash' scams have been prosecuted and imprisoned. See eg, T Thornhill, Crash for cash gang who staged car accidents to con insurance companies out of $£ 3$ million jailed (Daily Mail, 20 October 2011).

${ }^{112}$ See, eg, the case of Shah v Wasim Ul-Haq [2009] Court of Appeal (Civil Division) (EWCA Civ) 542 .

${ }^{113}$ The Government is currently considering ways of reducing fraudulent whiplash claims and on 2 May 2012 held a Whitehall 'summit' on the issue. Proposals include referring claimants to an independent panel of medical experts.

${ }^{114}$ Harris et al (fn 9) 65 ff. 
trade union, in the RTA context the advice came from a wider range of sources, including the police, breakdown companies, insurers, friends and relatives. This advice from third parties was important in providing reassurance not just about the strength of a claim but also of the appropriateness of claiming.

Arguably, those involved in an RTA may have a higher propensity to claim because the nature of the problem means they are more able and willing to move through the naming, blaming and claiming process than in other contexts. The identity of the defendant is usually clear and the cause of the accident and injury are easy to ascertain. In addition, because we are all familiar with driving, we are better able to assess whether negligence has occurred than in other contexts. Whilst we may be in a relationship with the driver at fault, any claim is less likely to damage that relationship than in the clinical or employment setting. Although the defendant in practice is an insurance company, the fact that the wrongdoer is an individual just like the claimant may make claiming less intimidating. Also, because we deal with car insurance ourselves, we are more familiar with the process if something goes wrong. All of these factors may play a role and, as a result, it may be that widespread 'no-win no-fee' advertising has been more effective in encouraging us to claim in this context. However, the strong culture of claiming can also be attributed to the following three inter-related institutional factors.

a) Those involved in an RTA are more likely to be contacted directly soon after the accident and encouraged to claim.

For most types of accident the claims market usually waits for potential claimants to contact them in response to their advertising. However, it is much more pro-active in relation to RTAs. Those involved are very likely to be contacted by a CMC and/or lawyer soon after the accident and encouraged to claim. This is because it is easier for the claims market to discover who has been involved in an RTA. Garages, breakdown companies and those involved in providing replacement vehicles sell on to CMCs the 
details of those who have suffered damage. ${ }^{115}$ Some CMCs have also engaged in datamining by recovering the names and addresses of people referred to CMCs but who did not claim at the time. They also obtain data from insurance comparison websites to pick up details of those who declared they had had an accident in the last three years. $^{116}$

Surprisingly, lawyers also receive details of potential RTA claimants from liability insurers. Whilst insurers have expressed concern that the payment of referral fees adds to the cost of resolving claims, some have decided to reduce their costs by selling on details of non-fault motorists who inform them of an accident on their policy. ${ }^{117}$ Indeed some insurers download their data to telesales companies who contact those involved in accidents to ascertain whether they are injured. ${ }^{118}$ Although the practice of paying for referrals has been in place for some time, the lifting of the ban in 2004 may go some way to explaining the increase in RTA claims since then. 'Third party capture' may also have contributed to this upward trend: from about 2005 insurers have tried to reduce the cost of resolving claims by making direct contact with those injured by their policyholders and offering them a settlement before they engage legal advice. ${ }^{119}$ There are even stories of accident victims being contacted by several different sources to encourage them to claim. ${ }^{120}$ The system of encouraging people to claim after an RTA is therefore now highly institutionalised and efficient when compared to other accidents.

${ }^{115}$ Ministry of Justice (fn 74) 211.

${ }^{116}$ A Ellis, Is data mining a major factor in the personal injury claims spike (Post Magazine, 1 November 2011).

${ }^{117}$ J Straw, Dirty secret that drives up motor insurance; Companies are selling drivers' details to claims firms exploiting no-win no-fee system (The Times, 27 June 2011).

${ }^{118}$ Ellis, Post Magazine, 1 November 2011.

${ }^{119}$ Financial Services Authority, Third Party Capture - What You Need to Consider, <http://www.fsa.gov.uk/pubs/other/third_party_capture.pdf $>$.

${ }^{120}$ Straw, The Times, 27 June 2011. 
b) The process for resolving RTAs is quicker, simpler and more routinised than that in place for other types of claim and has a higher rate of success.

As outlined in the first part of this article, the majority of claims are settled by insurers without the involvement of the courts. In order to process large numbers of low-value claims efficiently and economically, insurers have developed bureaucratic methods of handling claims. The role of fault has become diluted in practice and the system has become more liberal than if all cases went to court. The result is that RTA claims have a high success rate. As the number of RTA claims has increased over the years, so insurers' mechanisms for processing them have become more routinised and streamlined. This culminated in 2010 with the establishment of a 'portal' for RTA claims of up to $£ 10,000$ which provides swift, early electronic exchange of relevant claims information between claimant lawyers and insurers. ${ }^{121}$

Highly institutionalised remedy systems that are well known and readily available generally lead to higher rates of claiming for several reasons. ${ }^{122}$ They legitimise action by impliedly recognising 'the frequency and importance of a problem as well as the appropriateness of action taken in response to it'. ${ }^{123}$ They imply that claims are frequently successful so that it is worth having a go and they make claiming quick, cheap and stress-free and so reduce concerns about claiming. Finally, they can also encourage opportunistic and organised fraud because claims are not rigorously scrutinised or defended.

c) RTA claims are financially attractive to the legal services market.

The process for resolving RTA claims is very much a matter of routine. As a result they are financially attractive to lawyers because they can process them quickly and

\footnotetext{
${ }^{121}$ Pre-Action Protocol for Law Value Personal Injury Claims in Road Traffic Accidents and Practice Direction $8 \mathrm{~B}$ to the Civil Procedure Rules. See further, $J$ McQuater, The RTA Claims Process [2010] JPIL 103 and $R$ Hill, The New RTA Protocol (2010) 107(12) LS Gaz 29.

${ }^{122}$ RE Miller/A Sarat, Grievances, Claims and Disputes: Assessing the Adversary Culture (1980) L \& Soc Rev 525.

${ }^{123}$ Ibid, 564.
} 
cheaply. RTA claims are particularly attractive to the CFA market compared with more complex claims. Lawyers have reported that the way to make money is to have 'a regular throughput of small, easy cases' requiring only low investment to proceed. ${ }^{124}$ Because lawyers acting on a CFA basis are not paid until the conclusion of the claim it is also important that claims are resolved quickly. RTA claims fit this profile. Not only do they have a high rate of success meaning that the risk of 'no-fee' is very low, but their legal and factual simplicity means that they require only low investment and they are resolved quickly, thereby minimising problems with cash flow. In order to make money out of RTA claims on a CFA basis, however, it is necessary to process such claims in bulk using standardised documents and procedures. This increases the incentive for lawyers and CMCs to invest in the generation of RTA claims through direct contact and data-mining.

Overall, therefore, the process of encouraging, processing and resolving RTA claims is heavily institutionalised when compared to other types of claim. In addition, given their financial attractiveness, RTA claims have become more of a commodity. Whilst the impact of advertising is unclear, CFAs and payments for referral have certainly played a role in increasing our propensity to claim after an RTA. A circular process has occurred whereby demand has driven supply and supply has driven demand. It is clear that our propensity to claim compensation depends as much on institutionalised ways of handling different types of dispute as upon broader cultural propensities to litigate. ${ }^{125}$ Practices of claiming encouraged by this institutionalisation inevitably, however, feed into and become embedded in our wider culture. With claiming after an RTA becoming increasingly common, the experiences of other people may encourage us to claim because we feel that they are no more deserving. ${ }^{126}$ We may naturally think about compensation after an accident and even come to expect it. ${ }^{127}$ The overall

\footnotetext{
${ }^{124}$ Goriely/Moorhead/Abrams (fn 26) 21.

${ }^{125}$ Galanter (1983) 31 UCLA L Rev 4, 61.

${ }^{126}$ D Coates/S Penrod, Social Psychology and the Emergence of Disputes (1980-1) 15 L \& Soc Rev 655,658 .

${ }^{127}$ H Kritzer, Propensity to Sue in England and the United States of America: Blaming and Claiming in Tort Cases (1991) 18 J Law \& Soc 400, 420.
} 
result is that a stronger 'cultural link' has developed between RTAs, injury and compensation.

\section{Conclusion}

In this article we have outlined two sets of images of tort that are dominant in culture. The first set reflects various aspects of the traditional portrayal of justice. In contrast, the second group of images is more recent and relates to the development of a compensation culture. We have shown, in different ways and to different degrees, how these portrayals differ from the reality of tort in practice. In explaining how tort operates we have revealed significant features of the culture of tort. We have shown that tort in practice is heavily influenced by institutional arrangements. In the first part of the article we highlighted the influence of both welfare and insurance; in the second part our focus was upon the influence of the 'no-win no-fee' claims market which has developed in recent years. As a whole, the article shows how the operation of tort is heavily influenced by the commercial interests and economic demands of the institutions which surround it. In relation to the modern image, the commercial imperative of the claims market is well-known although it is much exaggerated outside the context of road traffic accidents. In relation to the traditional portrayal, however, the influence of insurance remains hidden and much under-estimated. Whilst the media ignore reality in favour of entertaining but worrying 'tort tales' of greedy claimants and ambulance-chasing lawyers, tort scholars continue to ignore reality in favour of theory and doctrine. They have done little to dispel the many myths. Cultural images of tort fail to reflect how the system of compensation for personal injury actually operates in practice. 